\title{
The ameliorative effect of vinpocetine on liver fibrosis and bone changes in the bile-duct ligated rat
}

\author{
Nabila S. Hassan ${ }^{\text {a,1,*}}$, Dalia M. Abouelfadl ${ }^{\text {a }}$, Omar M.E. Abdel-Salam ${ }^{\mathrm{b}}$ \\ a Department of Pathology, National Research Centre, Tahrir Street, Dokki, Cairo, Egypt \\ ${ }^{\mathrm{b}}$ Department of Toxicology and Narcotics, National Research Centre, Cairo, Egypt \\ 1 nabilas.hassan@yahoo.com \\ * corresponding author
}

\section{ARTICLE INFO}

Article history

Received June 25, 2020

Revised August 10, 2020

Accepted November 13, 2020

Keywords:

bile duct ligation

cholestatic liver disease

vinpocetine

\section{ABSTRACT}

Vinpocetine is a drug that is widely used to treat vascular cognitive disorders in the old age. The drug has been shown to protect against hepatocellular damage caused by carbon tetrachloride in rats. In this study, vinpocetine was investigated for its ability to improve cholestatic hepatic injury and bone changes associated with bile duct ligation in rats. Rats with biliary obstruction induced by double ligation and section of the common bile duct were randomly and blindly assigned to receive either vinpocetine $(2.1,4.2,8.4 \mathrm{mg} / \mathrm{kg})$ or saline once a day orally, starting one day after surgery and continued for one month thereafter. At the end of the treatment period, rats were killed and analyzed for blood biochemistry, liver and bone histopathology. Compared to their sham-treated counterparts, bile duct-ligated (BDL) rats exhibited markedly elevated serum activities of alanine aminotransferase (ALT), aspartate aminotransferase (AST), and alkaline phosphate (ALP) as well markedly raised serum bilirubin level. Histopathological examination of BDL rats revealed focal necrosis, degenerated hepatocytes, bile duct hyperplasia and inflammatory cell infiltrates. Histochemical staining using Feulgen and Periodic acid-Schiff's (PAS) staining showed depletion of liver glycogen and markedly decreased deoxyribonucleic acid (DNA) content in hepatocytes. Reduced osteocyte cellularity and few areas of regenerating bone were observed in BDL rats. The administration of vinpocetine to BDL rats resulted in dose-dependent decrease in serum ALT, AST, ALP activities by 33.6-64.4\%, 17.5$43.9 \%$ and $26.5 \%-39.2 \%$, respectively. Serum bilirubin decreased by $19 \%$ after $8.4 \mathrm{mg} / \mathrm{kg}$ of vinpocetine. The drug also resulted in amelioration of the pathological changes in the liver, increased glycogen and DNA content of hepatocytes and improved bone cellularity and increased bone regeneration dose-dependently. These findings suggest a beneficial effect for vinpocetine on liver damage and bone changes caused by biliary obstruction in rats.

This is an open access article under the CC-BY-SA license.

\section{Introduction}

The formation of bile is an essential function of the liver. This complex aqueous fluid consists mainly of water in which there is bile salts, bilirubin, proteins, cholesterol amino acids, steroids, xenobiotics. Bile which is primarily produced by hepatocytes and modified by cholangiocytes through secretion and absorption is necessary for the elimination of potentially toxic lipophyllic 
substances, and xenobiotics. Cholestasis results from the cessation or impairment of bile flow (Boyer, 2013). Cholestatic liver diseases encompasses a wide spectrum of disorders, the main pathological alteration in which is the cessation or stagnation of bile flow that occurs in conditions such as viral hepatitis, primary sclerosing cholangitis, septicaemia, biliary stricture, drug-induced cholestasis and many others (Pérez Fernández et al., 2004; Freedman, 2011). Cholestasis is associated with marked increase in liver bile acids and bilirubin levels and in regurgitation of these biliary constituents in the blood and other tissues. In the liver, this will eventually results in serious liver injury; the back pressure exerted by the stagnant bile on the liver cells causing anoxia and ischaemia as well as the toxic effects of the accumulated bile salts themselves results in hepatic injury. The failure to secrete bile or cholestasis will ultimately result in liver cirrhosis, and hepatocellular failure (Solter, 2005; Yang et al., 2010; Boyer, 2013). There is also an increase in the risk of developing hepatocellular or cholangiocellular carcinomas in ling-term cholestasis ( $\mathrm{Li}$ and Apte, 2015). Moreover, prolonged cholestasis such as that occurring in the context of primary sclerosing cholangitis is also an important factor in the development of osteoporosis in these patients (Le Gars, 2002; Gasser, 2009). In the management of cholestatic disorders, the primary goal is the alleviation of the underlying cause as well as improving the state of the liver cells eg., by the use of ursodeoxycholic acid or antioxidants like silymarin (Woolbright and Jaeschke, 2012). New therapeutic approaches are therefore needed to decrease liver injury and/or metabolic bone disease in cholestatic disorders.

Vinpocetine (vinpocetine-ethyl apovincaminate), the synthetic derivative of vincamine, an extract of periwinkle, is a drug that is widely used in the treatment of cognitive decline due to cerebrovascular insufficiency associated with aging by increasing cerebral blood flow and regional glucose uptake (Hadjiev 2003; Jovanović et al. 2013). Previously, vinpocetine has been shown to alleviate hepatocellular damage caused by the hepatotoxin carbon tetrachloride (CCl4) in the rat (Abdel-Salam et al., 2007). In this study, the effect of vinpocetine on liver tissue damage and fibrosis as well as on bone changes induced by bile-duct ligation in rats is examined. The latter is widely used to model human cholestatic liver disease (Kountouras et al., 1984; Salas et al., 2007; Sheen et al., 2016).

\section{Materials and methods}

\subsection{Animals}

Sprague-Dawley rats of either sex, weighing 180-200 g of body weight were used throughout the experiments. Animals were housed under standard laboratory conditions with free access to standard laboratory chow and water ad libitum. Animal procedures were performed in accordance with the Ethics Committee of the National Research Centre and followed the recommendations of the National Institutes of Health Guide for Care and Use of Laboratory Animals (Publication No. 85-23, revised 1985).

\subsection{Surgery}

Under light ether anaesthesia, midline laparotomy was performed, the common bile duct isolated and ligated with 4-0 silk suture in two places just above the duodenum anterior to the pancreas and posterior to the hilum of the liver. The bile duct was cut between the two ligatures and the abdominal wall was then closed in two layers by continuous silk suturing. Rats were given topical betadine as an antiseptic and $0.2 \mathrm{ml}$ gentamicin intramuscularly to control post-surgical infection. The rats were then allowed to recover with free access to food and water after the surgery. Sham operated rats were subjected only to midline laparotomy and manipulation of the bile duct.

\subsection{Study design}

Rats with ligation-section of the common bile duct were randomly and blindly assigned to different groups, six rats each. Rats received either vinpocetine $(2.1,4.2,8.4 \mathrm{mg} / \mathrm{kg}$ ) or saline. Drug treatment started 1 day after surgery and continued for 4 weeks. In Sham-ligated animals, the duct was located, manipulated, and replaced. At the end of the treatment period, rats were killed and 
analyzed for blood biochemistry and liver pathology. The doses were selected on the basis of previously published studies (Abdel-Salam et al., 2007).

\subsection{Biochemical assessment}

At the end of the experiments, blood samples were obtained from the retro-orbital vein plexuses, under ether anaesthesia. Alanine aminotransferase (ALT) and aspartate aminotransferase (AST) activities in serum were determined according to Reitman-Frankel colorimetric transaminase procedure (Crowley, 1967), whereas colorimetric determination of ALP activity was done according to the method of Belfield and Goldberg (1971) using commercially available kits (BioMérieux, France). Bilirubin in plasma was determined using commercially available kit (BioMérieux, France).

\subsection{Histopathological and histochemical evaluation}

After the end of the treatment period, rats were killed; livers and right tibia were excised and fixed in $10 \%$ formalin saline. Sections were prepared and stained with hematoxylin and eosin (H \& E) for histopathological examination. Histological investigations were carried out using Feulgen stain for deoxyribonucleic acid (DNA) content and Periodic acid-Schiff's (PAS) stain for hepatic glycogen distribution.

\subsubsection{Morphometric analysis}

Qwin Leica image processing and analysis system (Cambridge, UK) was used for the determination of the percentage of damaged areas (fibrosis and necrosis), DNA optical density, glycogen optical density, osteocytes measurements and the area of bone damage.

\section{Results}

\subsection{Effect of vinpocetine on serum liver enzymes and bilirubin in BDL rats}

Data are presented in Fig.1. Bile duct ligation for one month resulted in marked and significant elevation of alanine aminotransferase (ALT) and aspartate aminotransferase (AST) activities in serum by $355.6 \%$ and $685.8 \%$, respectively as compared with their sham control values $(98.4 \pm 4.7$ vs. $21.6 \pm 1.3 \mathrm{IU} / \mathrm{L}$ and $615.3 \pm 42.5 v s .78 .3 \pm 4.9 \mathrm{IU} / \mathrm{L}$, respectively). On the other hand, serum alkaline phosphatase activity increased by $590.2 \%(952.6 \pm 36.7 v s .138 .0 \pm 11.5 \mathrm{IU} / \mathrm{L})$. There was also significant elevation in serum bilirubin which reached $5.85 \pm 0.25 \mathrm{mg} / \mathrm{dl}$ compared with sham value of $0.24 \pm 0.04 \mathrm{mg} / \mathrm{dl}$. The administration of vinpocetine at doses of $2.1,4.2$ and $8.4 \mathrm{mg} / \mathrm{kg}$ caused a dose-dependent decrease in serum activities of ALT by $33.6 \%, 59.3 \%$ and $64.4 \%$, respectively. Similarly, AST activities fell by $17.5 \%, 21.3 \%$ and $43.9 \%$ and ALP activities decreased by $26.9 \%, 39.4 \%$ and $39.2 \%$ after treatment with the drug at the above doses compared with the corresponding BDL-saline control values. Serum bilirubin showed a $19 \%$ decrease after the highest dose of vinpocetine compared with the control group.

\subsection{Effect of vinpocetine on liver histopathological changes in BDL rats}

Liver sections from sham operated rats showed normal hepatic architecture (Fig. 2A). Liver sections of control rats with bile duct ligation revealed disorganization of hepatic cords, ballooning and fatty degeneration of hepatocytes, congested blood vessels with hyperplasia in bile ducts associated with inflammatory infiltrate. Focal areas of necrosis were seen (Fig. 2B \& C). Examination of liver sections from rats treated with vinpocetine revealed prominent improvement in cells structure and in bile duct hyperplasia. The highest dose of vinpocetine examined (8.4 $\mathrm{mg} / \mathrm{kg}$ ) showed the most prominent improvement in hepatocytes architecture and the number of binucleated cells is reduced (Fig. 2D-F). Quantitative image analysis of the area of damage on slides stained with haematoxylin and eosin is shown in Fig. 3. A dose-related decrease in the \% damaged area by $38.9 \%, 46.3 \%$ and $85.4 \%$ was seen after vinpocetine administration in $2.1 \mathrm{mg} / \mathrm{kg}$, $4.2 \mathrm{mg} / \mathrm{kg}$ and $8.4 \mathrm{mg} / \mathrm{kg}$, respectively as compared to the BDL-saline control group.

Joyce E. Idomeh et.al (Seasonal variation affects the physical and chemical parametes of inland waters) 

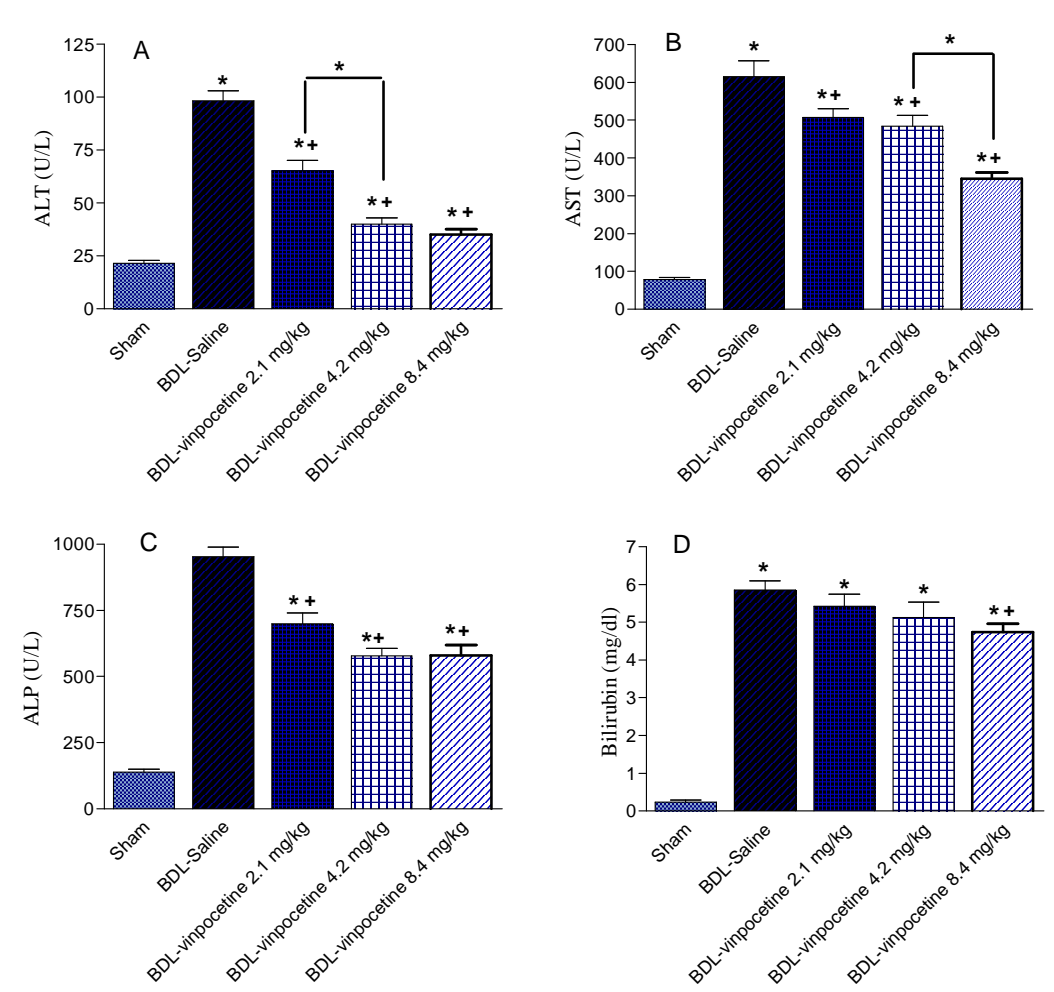

Fig. 1. Effect of vinpocetine on serum alanine aminotransferase (ALT), aspartate aminotransferase (AST), alkaline phosphatase (ALP), and bilirubin in bile-ligated rats. ${ }^{*} \mathrm{p}<0.05$ vs. Sham control and between different groups as shown on the graph. $+\mathrm{p}<0.05$ vs. BDL control.

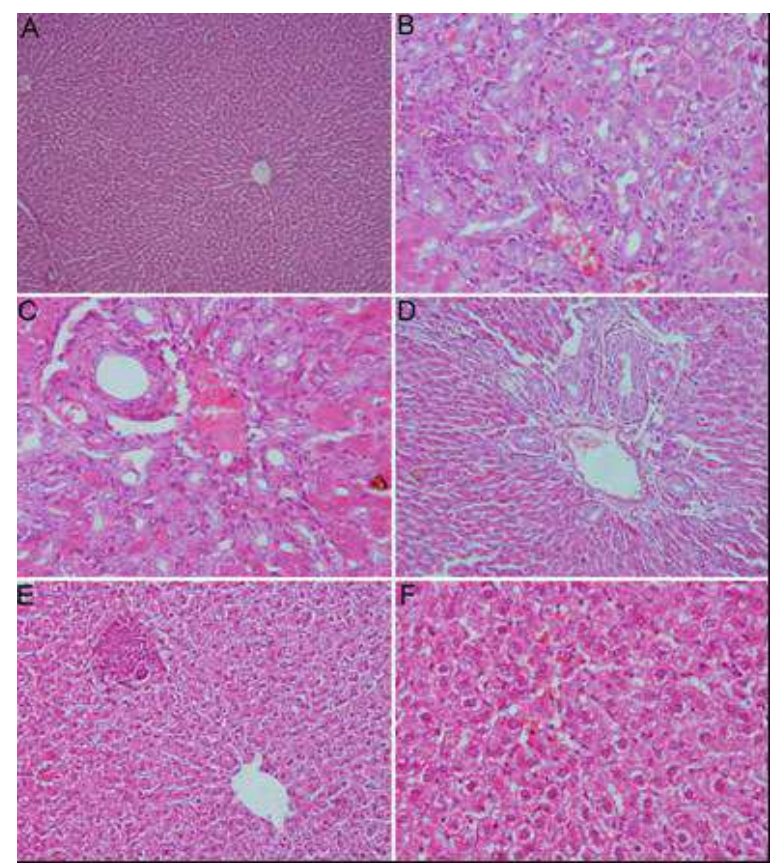

Fig. 2. Hx \& E stained sections from the liver of: (A) Sham control rat showing central veins, portal tracts and hepatic cords separated with blood sinusoids (X150). (B \& C) BDL rat with congestion, cytoplasmic necrosis, mononuclear cellular infiltration and fatty degeneration. Bile ducts show hyperplasia and/or damage (X400). (D) BDL + vinpocetine $2.1 \mathrm{mg} / \mathrm{kg}$ showing prominent improvement in cells structure and clear hypertrophy in bile duct hyperplasia (X300). (E \& F) BDL + vinpocetine 4.2 and $8.4 \mathrm{mg} / \mathrm{kg}$ hepatocytes showing prominent improvement in hepatocytes architecture and number of binucleated cells are seen (X150 $\& \mathrm{X} 400)$. 


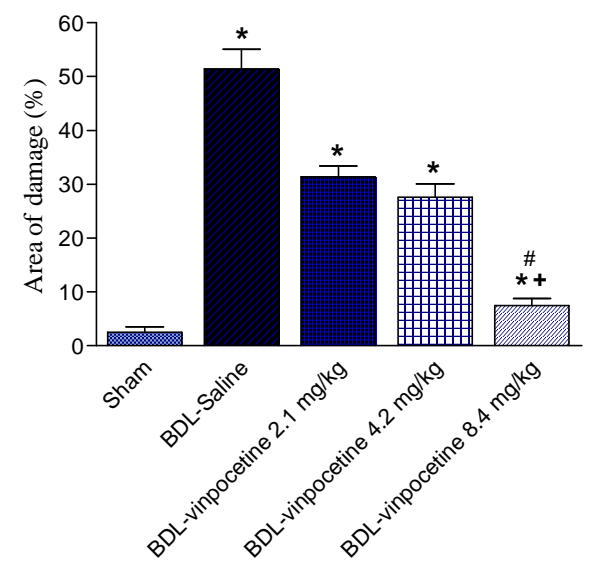

Fig. 3. The area of damage $(\%)$ in liver of BDL rats treated with different doses of vinpocetine. $* \mathrm{p}<0.05$ vs Sham contro. $+\mathrm{p}<0.05$ vs. BDL-saline

\subsection{Effect of vinpocetine on liver DNA in BDL rats}

The DNA reaction in BDL rats treated with saline showed marked decrease in DNA reaction and markedly increased inflammatory cells compared to sham operated rats (Fig. 4A \& 4B). Rats that received vinpocetine at $2.1 \mathrm{mg} / \mathrm{kg}$ showed mild decrease in DNA reaction in hepatocytes and marked increase in inflammatory cells (Fig. 4C). Rats treated with $4.2 \mathrm{mg} / \mathrm{kg}$ showed moderate decrease in DNA reaction in hepatocytes and marked increase in inflammatory cells (Fig. 4D), while rat given high dose of the drug $(8.4 \mathrm{mg} / \mathrm{kg})$ showed improvement in DNA reaction in hepatocytes and marked increase in inflammatory cells (Fig. 4E). The optical density of DNA content (\%) is shown in Fig. 5. The content of DNA fell by 30.1\% in BDL rats compared with the sham control group. Vinpocetine given to BDL rats at $4.2 \mathrm{mg} / \mathrm{kg}$ and $8.4 \mathrm{mg} / \mathrm{kg}$ caused significant increase in DNA by $26.6 \%$ and $41.8 \%$ content was seen after treatment with the drug at $8.4 \mathrm{mg} / \mathrm{kg}$ compared with the BDL-saline control group.

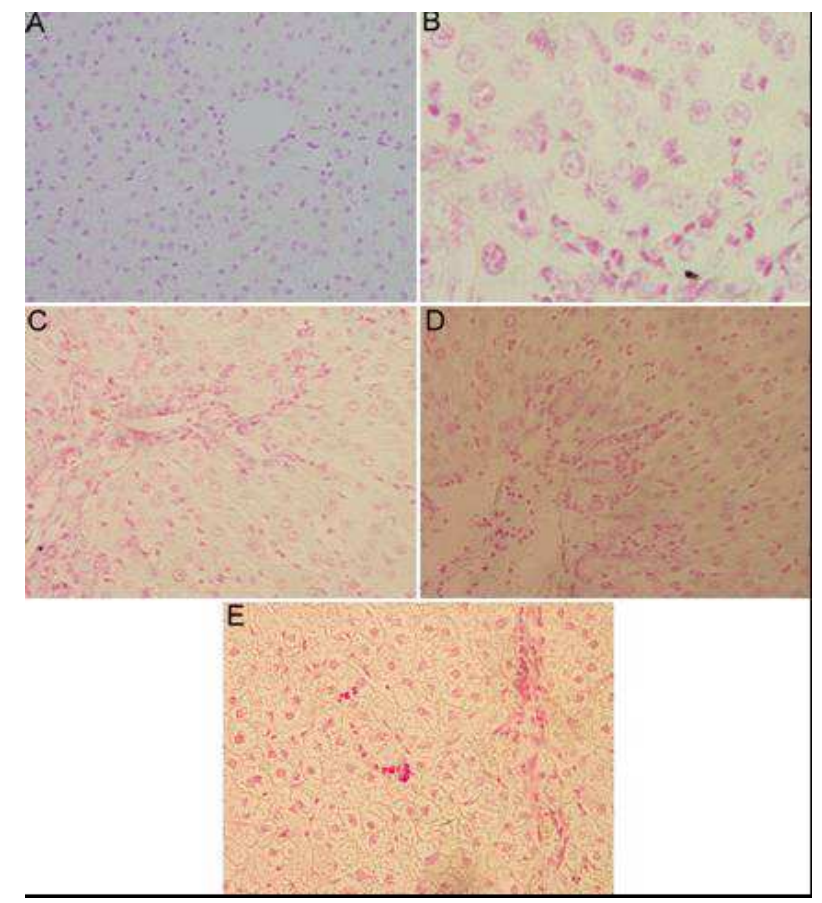

Fig. 4. Feulgen staining of sections from the liver of: (A) Sham control rat. (B) BDL rat showing marked decrease in DNA reaction. (C-E) BDL + vinpocetine showing dose-dependent increase in DNA reaction in hepatocytes (Feulgen X 400). 


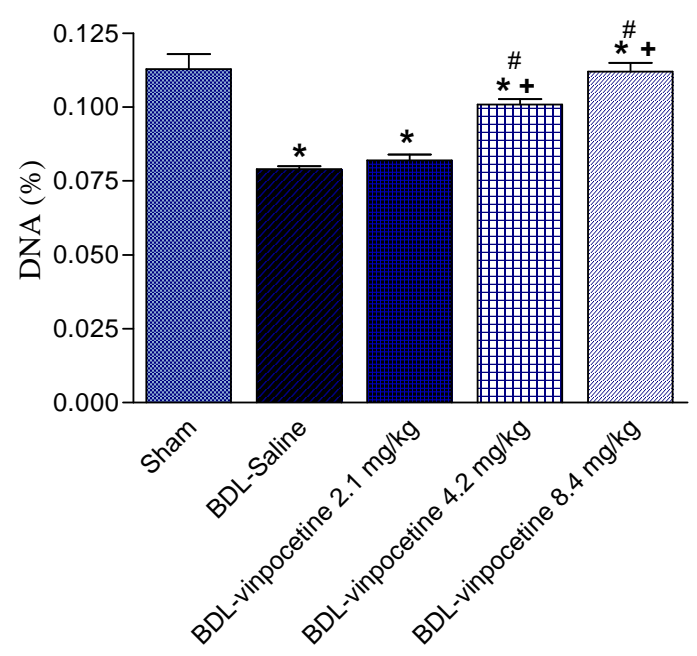

Fig. 5. DNA optical density (Feulgen stain) $(\%)$ in liver of BDL rats treated with different doses of vinpocetine. ${ }^{*} \mathrm{p}<0.05$ vs. Sham control. $+\mathrm{p}<0.05$ vs. BDL-saline. $\# \mathrm{p}<0.05$ vs. vinpocetine $2.1 \mathrm{mg} / \mathrm{kg}$

\subsection{Effect of vinpocetine on liver glycogen in BDL rats}

In bile duct ligated rats treated with saline hepatic glycogen distribution with Periodic acid-Schiff's (PAS) showed marked depletion compared with the sham control group (Fig. 6A \& 6B). Increased PAS staining for glycogen was increased by vinpocetine in a dose-dependent manner compared with BDL control group (Fig. 6C-E). The optical density of glycogen content (\%) is shown in Fig. 7. Significant increase in glycogen content was seen after treatment with the drug at $8.4 \mathrm{mg} / \mathrm{kg}$ compared with the BDL-saline control group.

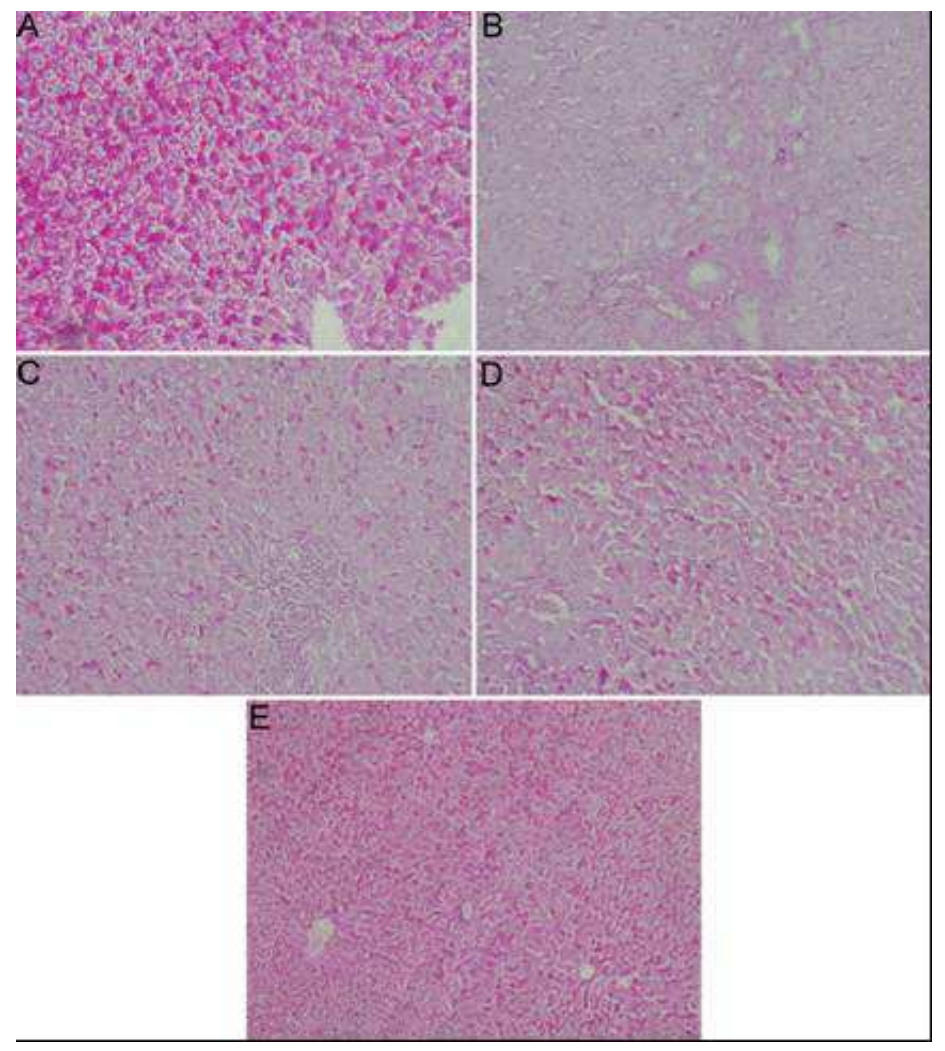

Fig. 6. Periodic acid-Schiff's staining of sections from the liver of: (A) Sham control rat. (B) BDL rat showing marked depletion in hepatic glycogen. (C-E) BDL + vinpocetine showing dose-dependent increase in glycogen content in hepatocytes (PAS X150). 


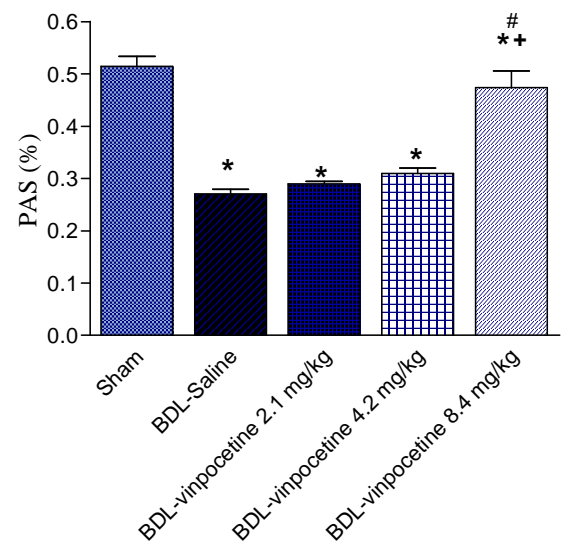

Fig. 7. Glycogen optical density (\%) (Periodic acid-Schiff's stain) in liver of BDL rats treated with different doses of vinpocetine. ${ }^{*} \mathrm{p}<0.05$ vs. Sham control. $+\mathrm{p}<0.05$ vs. BDL-saline. \#p $<0.05$ vs. vinpocetine 2.1 or vinpocetine $4.2 \mathrm{mg} / \mathrm{kg}$

\subsection{Effect of vinpocetine on bone histopathological changes in BDL rats}

Sections from the bone in sham control rats revealed average osteocyte cellularity and distribution, normal mineralization pattern and few areas of regenerating bone (Fig. 8A). In contrast, BDL rats showed decreased osteocytic count and few areas of bone regeneration (Fig. 8B). In the rats treated with lowest dose of vinpocetine the osteocyte cellularity was improved and more areas of bone basophilic cartilaginous tissue appeared within the bone tissue representing areas of regeneration started to increased (Fig. 8C). Both parameters improved the most in the group receiving the highest doses of vinpocetine (Fig. 8D \& 8E). The comparison of bone sections between different groups using the image analyzer morphometric studies revealed decrease in osteocyte count and the areas of regenerating new bone formation in the BDL group and a dose dependent improvement in such parameters in the vinpocetine groups (Figs. $9 \& 10$ ).

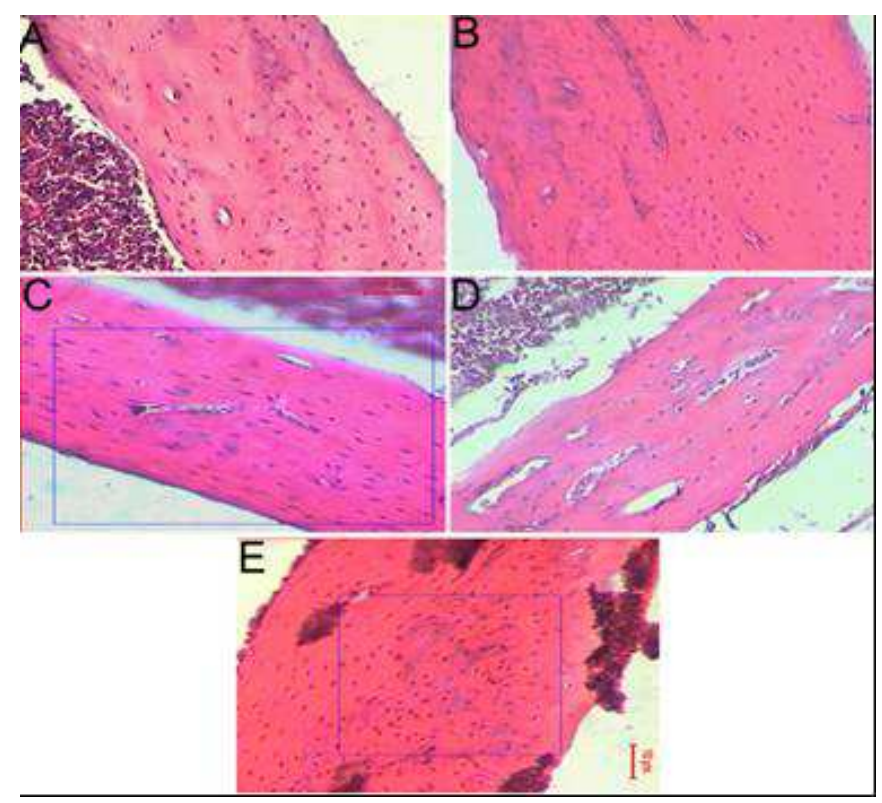

Fig. 8. A photomicrograph of the bone cortex from (A) Sham treated rat showing well-formed cortical bone with osteocyte cellularity. (B) BDL rats showing decreased osteocyte count and regenerative bone islands (C) $\mathrm{BDL}+$ vinpocetine $2.1 \mathrm{mg} / \mathrm{kg}$ showing more compact appearance of the shaft and increased osteocyte cellularity with rounded nuclei (D) BDL + vinpocetine $4.2 \mathrm{mg} / \mathrm{kg}$ showing improved cell count and bone regeneration $(\mathrm{E}) \mathrm{BDL}+$ vinpocetine $8.4 \mathrm{mg} / \mathrm{kg}$ with more osteocytes and islands of bone regeneration (HX.\& E.X100). 


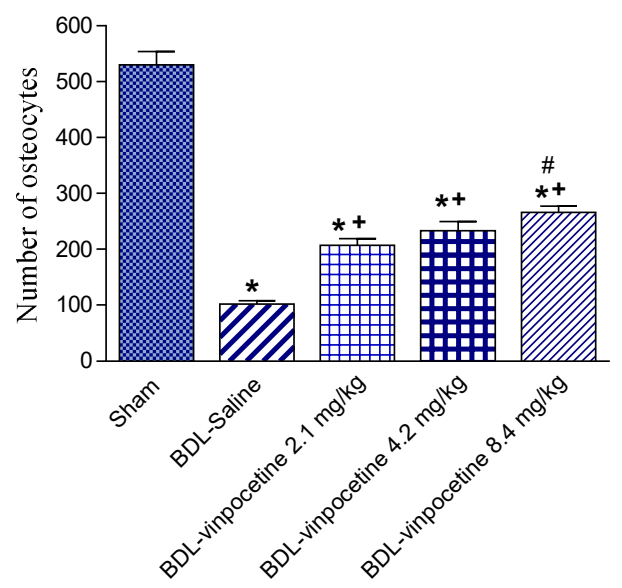

Fig. 9. Osteocyte count (mean \pm SEM) in bone of BDL rats treated with different doses of vinpocetine. $* \mathrm{p}<0.05$ vs. Sham control. $+\mathrm{p}<0.05$ vs. BDL-saline. \#p<0.05 vs. vinpocetine 2.1 or vinpocetine $4.2 \mathrm{mg} / \mathrm{kg}$

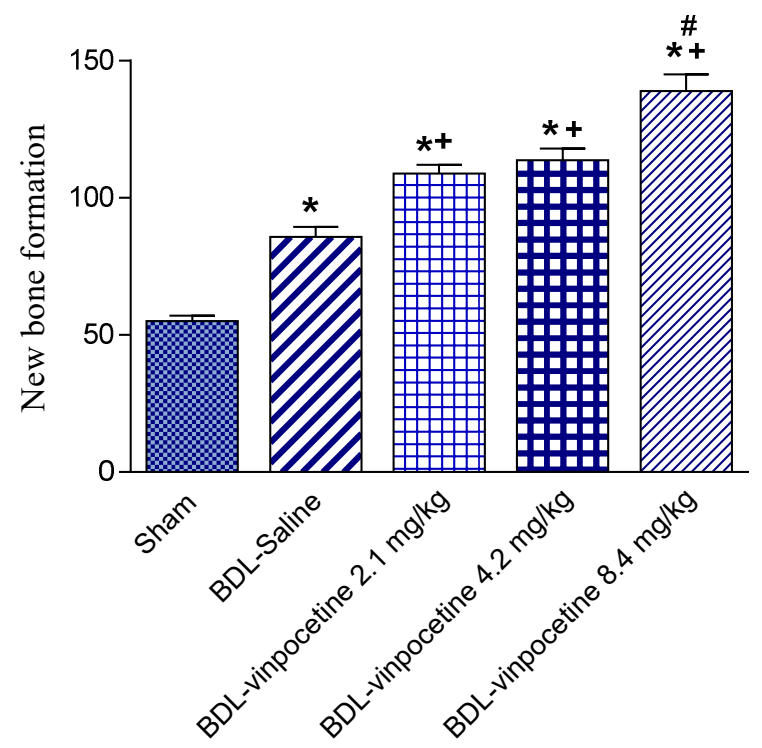

Fig. 10. Areas of new bone formation (mean \pm SEM) in bone of BDL rats treated with different doses of vinpocetine. ${ }^{*} \mathrm{p}<0.05$ vs. Sham control. $+\mathrm{p}<0.05$ vs. BDL-saline. \#p<0.05 vs. vinpocetine 2.1 or vinpocetine $4.2 \mathrm{mg} / \mathrm{kg}$

\section{Discussion}

The rat bile duct ligation model is a widely used one that mimics in many aspects the condition of biliary obstruction in humans such as that occurring in biliary atresia and primary sclerosing cholangitis. The model offers the opportunity to study both the acute and chronic sequel of obstruction to bile flow such as the complicating fibrosis, sepsis and brain oedema (Yang et al., 2010; Yang et al., 2015). In this study, bile duct ligation for one month caused significantly elevated serum activities of ALT and AST. These hepatocellular enzymes are released into the circulation upon damage to hepatocytes in amounts that is dependent on the extent of liver damage. There was also markedly increased serum ALP activity. Alkaline phosphatase is a cell wall enzyme and its synthesis and release from cell surface increases when there is stagnation to bile flow (Giannini et al., 2005). Markedly increased activity of ALP in liver and serum is detectable within 12h after bile duct ligation (Kaplan, 1979, 1983). The increased serum ALP activity therefore reflects the severity of biliary obstruction. The present study also showed that on histopathological examination, the liver tissue suffered ballooning of hepatocytes, fatty degeneration, inflammatory cell infiltration, bile duct hyperplasia and focal necrosis. These results are consistent with the 
pathological alterations reported in this model. In their study, Zepeda-Morales et al. (2016) found extensive bile duct proliferation and periductal fibrosis after one month of bile duct ligation in the rat. Other authors reported ductular proliferation and an increase in periportal collagen eight weeks after bile duct ligation in rats (Salas et al., 2007). Inflammation is a hallmark of cholestasis due to the action of the hydrophobic bile salts on the liver parenchyma (Zollner and Trauner, 2006; Wenniger and Beuers, 2010). Following bile duct ligation there is time-dependent inflammatory cell infiltration starting from the seventh day after surgery and decreases with the development of fibrosis around two weeks post-obstruction (Alcarz et al., 2008). One of the important metabolic functions of the liver is the regulation of carbohydrate metabolism through glycogensis, glycogenolysis and gluconeogenesis (Giannini et al., 2005). Liver glycogen thus reflects the synthetic capacity of the liver and is subject to alterations in liver disease. In this study, marked depletion of glycogen was observed in hepatocytes from bile duct ligated rats.

Osteopenic bone disease is also an important feature complicating long standing cholestasis (Le Gars, 2002; Patel and Munoz, 2015). Osteoporosis has been reported in 15\% of patients with primary sclerosing cholangitis (Angulo et al., 2011). Several factors underlie the occurrence of metabolic bone disease in these patients including decreased liver synthetic capacity with decreased formation of fibronectin, Insulin-like growth factor-I, impaired hydroxylation of vitamin D and increased levels of cytokines (Nakchbandi et al., 2014). In the present study bile duct ligation for one month caused decreased osteocyte count and regenerative bone islands. These findings are consistent with earlier observations (Abdel-Salam et al., 2008a,b) and suggest the suitability of this model to study the pathogenetic mechanisms of bone changes in conditions of chronic cholestasis.

Our results show that the administration of vinpocetine was able to ameliorate the increase and to decrease liver damage and to lessen the extent of fibrosis as well as maintain the liver architecture. Vinpoectine also caused marked improvement in the pathological bone changes due to bile duct ligation. These data support the findings in the $\mathrm{CCl}_{4}$ model of hepatotoxicity (Abdel-Salam et al., 2007) and in hepatic ischaemia/reperfusion injury (Zaki and Abdelsalam, 2013). The mechanism by which vinpocetine protects against the bile salt toxicity is not clear. Vinpocetine is widely prescribed to treat chronic cerebral hypoperfusion and the consequent cognitive deficits that occur due to aging (Patyar et al., 2011). Initially, augmentation of cerebral blood flow and metabolism has been suggested to account for the drug effects (Hadjiev 2003; Jovanović et al. 2013). Recently, vinpocetine was found to possess anti-inflammatory actions by decreasing the release of the proinflammatory cytokines such as tumour necrosis factor-alpha (TNF- $\alpha$ ), interleukin-1 $\beta$ (IL-1 $\beta$ ), IL-1 $\alpha$, and IL-8 (Gómez et al., 2013; Liu et al., 2014). Vinpocetine was also shown to have antioxidant potential (Abdel-Salam et al., 2011; Zaki and Abdelsalam, 2013) and to increase glucose availability to tissues (Nivison-Smith et al., 2015). Vinpocetine might therefore protect against liver damage caused by bile duct ligation by decreasing inflammation and oxidative stress.

\section{Conclusion}

At the present time, the use of hydrophilic bile acid ursodeoxycholic acid is the only available treatment for chronic cholestasis (Wenniger and Beuers, 2010). The present study suggests that vinpocetine could be useful in this condition by itself or as an "add on" therapy to ursodeoxycholic acid.

\section{Conflicts of interest}

The authors declare that there are no potential conflicts of interest.

\section{Acknowledgement}

This works is was not supported by research grants 


\section{References}

[1] Abdel Salam, O.M.E., Oraby, F.H., Hssan, N.S., 2007. Vinpocetine ameliorates acute hepatic damage caused by dministration of carbon tetrachloride in rats. Acta Biologica Hungarica. 58 (4), 411-419.

[2] Abdel-Salam, O.M., Khadrawy, Y.A., Salem, N.A., Sleem, A.A., 2011. Oxidative stress in a model of toxic demyelination in rat brain: the effect of piracetam and vinpocetine. Neurochem. Res. 36(6),1062-72. doi: 10.1007/s11064-011-0450-1.

[3] Abdel Salam, O.M.E., Nofal, S.M.., El-Shenawy, S.M., Shaffie, N.M., 2008a. The effect of interferon alone or combined with silymarin on liver and bone parameters in bile duct ligated rats: The Internet Journal of Pharmacology 6 (1).

[4] Abdel Salam, O.M.E., Nofal, S.M.., El-Shenawy, S.M., Shaffie, N.M., 2008b. Effect of piperine on liver damage and bone changes caused by bile duct ligation in rats: The Internet Journal of Pharmacology 5, (2).

[5] Alcaraz, A., Hernández-Espinosa, D., Iyú, D., Mota-Blanco, R., Atucha, N., Ortiz-Ruiz, A., GarcíaEstañ, J., Ortiz, M., 2008. Effects of chronic L-NAME on nitrotyrosine expression and renal vascular reactivity in rats with chronic bile-duct ligation. Clinical science (London, England). 115, 57-68. 10.1042/CS20070312.

[6] Angulo, P., Grandison, G.A., Fong, D.G., Keach, J.C., Lindor, K.D., Bjornsson, E., Koch, A., 2011. Bone disease in patients with primary sclerosing cholangitis. Gastroenterology 140(1), 180-188. doi:10.1053/j.gastro.2010.10.014.

[7] Belfield, A., Goldberg, D.M., 1971. Revised assay for serum phenyl phosphatase activity using 4amino-antipyrine. Enzyme 12, 561-573.

[8] Boyer, J.L., 2013. Bile formation and secretion. Compr. Physiol. 3(3), 1035-1078. doi: 10.1002/cphy.c120027.

[9] Crowley, L.V., 1967. The Reitman-Frankel colorimetric transaminase procedure in suspected myocardial infarction. Clin. Chem. 13, 482-487.

[10] Freedman, N.D., Curto, T.M., Morishima, C., Seeff, L.B., Goodman, Z.D., Wright. E.C., et al., 2011. HALT-C Trial Group. Silymarin use and liver disease progression in the Hepatitis C Antiviral LongTerm Treatment against Cirrhosis trial. Aliment. Pharmacol. Ther. 33,127-137.

[11] Gasser, R.W., 2008. Cholestasis and metabolic bone disease -a clinical review. Wien Med Wochenschr. 158/19-20: 553-557. DOI 10.1007/s10354-008-0594-z.

[12] Giannini, E.G., Testa, R., Savarino, V., 2005. Liver enzyme alteration: A guide for clinicians. C.M.A.J. 172(3),367-79. doi: 10.1503/cmaj.1040752.

[13] Gómez, C.D., Buijs, R.M., Sitges, M., 2014. The anti-seizure drugs vinpocetine and carbamazepine, but not valproic acid, reduce inflammatory IL-1 $\beta$ and TNF- $\alpha$ expression in rat hippocampus. J. Neurochem. 130(6),770-9. doi: 10.1111/jnc.12784.

[14] Hadjiev, D., 2003. Asymptomatic ischemic cerebrovascular disorders and neuroprotection with vinpocetine. Ideggyógy. Szemle 56, 166-172. 
[15] Jovanović, Z., Pavlović, A., Pekmezovic, T., Mijajlovic, M., Covicković, N., 2013. Transcranial Doppler assessment of cerebral vasomotor reactivity in evaluating effects of vinpocetine in cerebral small vessel disease: A pilot study. Ideggyógyászati szemle 66, 263-268.

[16] Kaplan, M.M., 1979. Induction of rat liver alkaline phosphatase by bile duct ligation. Yale. J. Biol. Med. 52(1), 69-75.

[17] Kaplan, M.M., Ohkubo, A., Quaroni, E.G., Sze-Tu. D., 1983. Increased synthesis of rat liver alkaline phosphatase by bile duct ligation. Hepatology 3(3), 368-76. doi: 10.1002/hep.1840030315.

[18] Kountouras, J., Billing, B.H., Scheuer, P.J., 1984. Prolonged bile duct obstruction: a new experimental model for cirrhosis in the rat. Br. Exp. Path. 65, 305-311.

[19] Le Gars, L., 2002. Bone involvement in patients with chronic cholestasis. Joint Bone Spine 69, 373378.

[20] Li, T., Apte, U., 2015. Bile acid metabolism and signaling in cholestasis, inflammation, and cancer. Adv. Pharmacol. 74, 263-302. doi: 10.1016/bs.apha.2015.04.003.

[21] Liu, R.T., Wang, A., To, E., Gao, J., Cao, S., Cui, J.Z., et al., 2014. Vinpocetine inhibits amyloid-beta induced activation of NF-KB, NLRP3 inflammasome and cytokine production in retinal pigment epithelial cells. Exp. Eye. Res. 127, 49-58. doi: 10.1016/j.exer.2014.07.003.

[22] Nakchbandi, A.I., 2014. Osteoporosis and fractures in liver disease: Relevance, pathogenesis and therapeutic implications. World. J. Gastroenterol. 20(28), 9427-9438.

[23] Nivison-Smith, L., O’Brien, B.J., Truong, M., Guo, C.X., Kalloniatis, M., Acosta, M.L., 2015. Vinpocetine modulates metabolic activity and function during retinal ischemia. Am. J. Physiol. Cell. Physiol. 308, C737-C749.

[24] Patel, N., Munoz, S.W., 2015. Bone disease in cirrhosis. Clinical Liver Disease 6(4), 96-99.

[25] Patyar, S., Prakash, A., Modi, M., Medhi, B., 2011. Role of vinpocetine in cerebrovascular diseases. Pharmacol. Rep. 63(3), 618-628.

[26] Pérez Fernández, T., López Serrano, P., Tomás, E., Gutiérrez, M.L., Lledó, J.L., Cacho, G., et al., 2004. Diagnostic and therapeutic approach to cholestatic liver disease. Rev Esp Enferm Dig (Madrid) 96(1), 60-73.

[27] Salas, A.L., Ocampo, G., Fariña, G.G., Reyes-Esparza, J., Rodríguez-Fragoso, L., 2007. Genistein decreases liver fibrosis and cholestasis induced by prolonged biliary obstruction in the rat. Ann. Hepatol. 6(1), 41-47.

[28] Sheen, J.M., Chen, Y.C., Hsu, M.H., Tain, Y.L., Huang, Y.H., Tiao, M.M., et al., 2016. Melatonin alleviates liver apoptosis in bile duct ligation young rats. Int. J. Mol. Sci. 17, 1365. doi:10.3390/ijms17081365.

[29] Solter, P.F., 2005. Clinical pathology approaches to hepatic injury. Toxicologic Pathology 33, 9-16.

[30] Wenniger, L.M., Beuers, U., 2010. Bile salts and cholestasis. Dig. Liver. Dis. 42(6),409-418. doi: 10.1016/j.dld.2010.03.015.

[31] Woolbright, B.L., Jaeschke, H., 2012. Novel insight into mechanisms of cholestatic liver injury. World J. Gastroenterol. 18(36), 4985-4993.

[32] Yang, F., Gaudio, E., Onori, P., Wise, C., Alpini, G., Glaser, S.S., 2010. Mechanisms of biliary damage. J Cell Death 3, 13-21. 
[33] Yang, Y., Chen, B., Chen, Y., Zu, B., Yi, B., Lu, K., 2015. A comparison of two common bile duct ligation methods to establish hepatopulmonary syndrome animal models. Lab. Anim. 49(1), 71-9. doi: 10.1177/0023677214558701.

[34] Zaki, H.F., Abdelsalam, R.M., 2013. Vinpocetine protects liver against ischemia-reperfusion injury. Can. J. Physiol. Pharmacol. 91(12), 1064-70. doi: 10.1139/cjpp-2013-0097.

[35] Zepeda-Morales, S., Del Toro-Arreola, S., Sánchez-Orozco, L., Fafutis-Morris, M., García-Benavides, L., Pereira-Suárez, A.L., et al., 2013. Experimenrtal cholestasis is associated with increased IL-17 and IFN- $\alpha$ expression. Frontiers in Immunology 4. 10.3389/conf.fimmu.2013.02.00211.

[36] Zollner, G., Trauner, M., 2006. Molecular mechanisms of cholestasis. Wien. Med. Wochenschr. 156(13-14), 380-385. 